\title{
HISTÓRIA, HISTORIOGRAFIA E EDUCAÇ̃̃O: PRESSUPOSTOS TEÓRICO-METODOLÓGICOS
}

\author{
Jeferson Anibal Gonzalez ${ }^{1}$ \\ FE/UNICAMP \\ jefersonag@yahoo.com.br
}

\section{RESUMO:}

$\mathrm{O}$ artigo está dividido em três partes. Na primeira, discute-se brevemente as questões referentes ao conceito de História e às escolas históricas. Posteriormente, identifica-se a concepção de História sustentada pelo materialismo histórico, contrapondo-a ao paradigma pós-moderno. Por fim, ressalta-se os pressupostos teórico-metodológicos da pesquisa histórico-educacional que busquem compreender a essência do fenômeno educativo, suas contradições, mediações e determinações; pressupostos que proporcionem uma maior compreensão da realidade e que ao mesmo tempo apontem uma estratégia política para a transformação dessa mesma realidade.

Palavras-Chave: Teorias da história. Pesquisa histórico-educacional. Materialismo histórico-dialético.

\section{HISTORY, HISTORIOGRAPHY AND EDUCATION: THEORETICAL AND METHODOLOGICAL ASSUMPTIONS.}

ABSTRACT:

This paper is divided into three parts. Initially we discuss briefly the questions related to the concept of history and the historical schools. After, we identified the conception of history supported by historical materialism, in contrast to the post modern paradigm. Ultimately we emphasize the assumption theoretical and methodological of the research educational and historical that seek to understand the essence of the educational phenomenon, their contradictions and determinations; assumptions that provided greater understanding of the reality and pointing a political strategy to the transformation of this reality.

Keywords: theories of history, historical and educational research, historical dialectical materialism.

\section{INTRODUÇÃO}

A multiplicidade de enfoques, tendências e movimentos fazem do campo historiográfico em geral e da pesquisa histórico-educacional em particular, uma arena de constantes debates. Muitas vezes sufocados pela hegemonia do irracionalismo, subjetivismo e individualismo exacerbado, esses debates são de vital importância à produção de conhecimento sobre a materialidade histórica, pois refletem os diferentes posicionamentos políticos numa sociedade de classes sociais antagônicas. Assim, compreender a produção desse conhecimento é parte essencial à compreensão da própria dinâmica social na qual se inserem os autores filiados nas diferentes escolas históricas. 
Tendo isso em vista e apoiado nas leituras e discussões realizadas durante a disciplina Metodologias da História e Educação, ministrada pelo Prof. Dr. José Luis Sanfelice ao longo do segundo semestre de 2009 no programa de pós-graduação em Educação da FE/UNICAMP, o presente trabalho tem por objetivo contribuir para o debate teórico-metodológico da pesquisa histórico-educacional. Para isso, primeiramente discute as questões referentes ao conceito de História e às escolas históricas, passando pela história tradicional, o positivismo, o historicismo e a escola dos Annales. No segundo item, identifica-se a concepção de História sustentada pelo materialismo histórico-dialético, enraizada nas determinações políticas, econômicas e sociais, contrapondo-a ao paradigma pós-moderno. Trilhado esse caminho, por fim se apresenta algumas categorias e pressupostos da pesquisa histórico-educacional animada pelo materilaismo histórico dialético.

\section{HISTÓRIA E HISTORIOGRAFIA}

Como integrante do campo das chamadas Ciências Sociais ou humanas, o conhecimento histórico caracteriza-se pela especificidade da relação entre o sujeito e o objeto de conhecimento. Nesse sentido, pode-se dizer que a história é construída à medida que os seres humanos produzem materialmente a sua existência e, por seguinte, as bases políticas, econômicas e culturais da sociedade. Segundo Saviani (2000), ao transformar a natureza em objeto de sua ação é que os seres humanos rompem com a visão cíclica do tempo, passando a compreendê-lo como:

(...) uma linha progressiva que se projeta para a frente, ligando o passado ao futuro por meio do presente. Surge aí a questão de se compreender a causa, o significado e a direção das transformações. A História emerge, pois, com um problema não apenas prático, mas também teórico. $\mathrm{O}$ homem além de um ser histórico, busca agora apropriar-se da sua historicidade. Além de fazer história, aspira a se tornar consciente dessa sua identidade. (SAVIANI, 2000, p.8)

No processo de produção do conhecimento, o sujeito imprime em seu trabalho um olhar determinado pelas condições de produção desse conhecimento. Esses diferentes olhares formam as chamadas Escolas Históricas, que aglutinam os diversos autores ao longo do tempo a partir de características gerais e específicas do conhecimento que produziram. Isso possibilita, por exemplo, falar em "história tradicional" e "escola dos Annales", entre outros.

Bourdé e Martin (1990, p.44) indicam que de gênero literário na Antiguidade e na Idade Média, o conhecimento histórico passa a se constituir em "filosofias da história" com as luzes do século XVIII, quando pensadores como Voltaire, Kant e Condorcet, tomados pelas idéias do devir da matéria, da evolução das espécies e do progresso dos seres humanos, "acreditam num movimento ascendente da humanidade em direção a um Estado ideal". No século XIX, ainda há predominância da especulação filosófica da história em relação à história como fazer científico especializado, sendo expressão desse momento o idealismo alemão nas figuras de Schilling, Fichte e, principalmente, Hegel (CASTANHO, 2006, p.140).

Seguindo a linha da racionalidade científica, sob os auspícios do positivismo, defende-se que o conhecimento histórico deve ser construído sem a interferência das visões particulares, supondo-se que a garantia da objetividade se encontra na neutralidade do 
cientista em relação ao objeto de pesquisa. Analisando a questão do relacionamento entre as visões de mundo e o processo de produção do conhecimento científico, Löwy (1992; 2000) identifica três pressupostos sustentados pelo positivismo: 1) as leis que regulam o funcionamento da sociedade são do mesmo tipo das leis que regem as leis naturais; 2) os métodos de estudo da sociedade devem ser os mesmo métodos de estudo da natureza; 3 ) a ciência social, assim como a natural, deve ser objetiva, neutra, sem a interferência das visões de mundo. Mas qual a influência desses pressupostos na historiografia? A cientificidade nos moldes do positivismo apregoou a História como descrição fidedigna dos fatos do passado, o que desaguou nas narrativas dos grandes heróis e seus feitos que garantiram a ordem e o progresso ${ }^{2}$. A esse "tipo" de historiografia, surgiram diversas reações, principalmente por parte do marxismo - tratado neste trabalho em item posterior , do historicismo relativista e da chamada Escola dos Annales.

A reação historicista relativista pode ser considerada não somente em relação ao positivismo, mas ao conjunto das teorias que pressupunham a racionalidade do processo de produção do conhecimento científico, o que leva Saviani (2000, p. 9) a identificar autores como Dilthey e Spengler, ligados a esse referencial, com certa "reação anti-racionalista ocorrida na virada do século XIX para o século XX". Löwy $(1992 ; 2000)$ aponta três pressupostos também para o historicismo ${ }^{3}$ : 1) todo fenômeno social é histórico; 2) os fatos sociais ou históricos são diferentes dos fatos naturais; 3) não só o objeto, mas também o pesquisador está imerso na história. Este último pressuposto configurou-se como ponto principal de sustentação do historicismo relativista, do qual Droysen retira a seguinte conclusão: se pesquisador e objeto encontram-se imersos na história, logo a possibilidade de um conhecimento objetivo, neutro é nula, viabilizando-se somente visões parciais e unilaterais. Outro posicionamento no mesmo sentido é o de Simmel que considera, em contraposição à idéia positivista do conhecimento enquanto reflexo fiel da realidade, o conhecimento enquanto uma pintura na qual o artista (pesquisador) reproduz a realidade, porém com traços particulares e cores de sua preferência. Esse posicionamento faz com que Simmel conclua pela impossibilidade de qualquer verdade que tome as diferentes visões, numa síntese de pontos de vista, ou seja, o autor procura resolver a problemática pela via do ecletismo. Segundo Löwy (1992, p.78):

É nesse ponto que chega o historicismo: descobriu a relatividade histórica do conhecimento, descobriu a delimitação unilateral de toda a interpretação científica da realidade, desmistificou as ilusões positivistas de um conhecimento absoluto, neutro, da realidade, mostrou a importância de se dar conta da especificidade, da particularidade do conhecimento científico da sociedade, das diferenças entre o conhecimento social e os conhecimentos das ciências naturais. Mas não conseguiu superar os dilemas do relativismo, para qual todo conhecimento é parcial e subjetivo. A única solução que ele encontrou através de alguns autores, foi uma solução fraca, inconseqüente, de pouca força, que foi o ecletismo, a síntese, o compromisso, a via média, etc.

Se a questão para o historicismo relativista é a impossibilidade da neutralidade do sujeito que conhece em relação ao objeto de conhecimento, o que o leva a recolher as partículas das diferentes visões pela via do ecletismo, os Annales, em suas duas primeiras gerações vão se apegar à interdisciplinaridade, ou seja, aos objetos, métodos e técnicas das diferentes ciências, com o objetivo de se construir racionalmente uma visão totalizante da história - objetivo abandonado pela terceira geração em favor das migalhas da história. Mas como se constitui o movimento dos Annales? 
O movimento dos Annales $^{4}$ constituiu-se por pesquisadores organizados em torno da revista acadêmica Revue des Annales. Peter Burke (1997, pp.17-18) resumiu as idéias diretrizes da revista:

Em primeiro lugar, a substituição da tradicional narrativa de acontecimentos por uma história-problema. Em segundo lugar, a história de todas as atividades humanas e não apenas história política. Em terceiro lugar, visando completar os dois primeiros objetivos, a colaboração com outras disciplinas, tais como a geografia, a sociologia, a psicologia, a economia, a lingüística, a antropologia social, e tantas outras.

Longe de significar um movimento coeso, homogêneo, sem contradições, pode-se dividir a história dos Annales em três gerações: $1^{\text {a }}$ ) de 1920-1945 - formada pelos seus fundadores, Lucien Febre e Marc Bloch, caracterizou-se pela busca da História globalizante em oposição à história factual tradicional; $2^{\mathrm{a}}$ ) após a Segunda Guerra Mundial até 1968, dominada pela presença de Fernand Braudel, caracterizou-se por cunhar conceitos e métodos diferenciados; $3^{\mathrm{a}}$ ) inicia-se por volta de 1968 tendo como nome principal o do historiador Jacques Le Goff, caracterizou-se principalmente pela diversificação e fragmentação dos temas. Esta geração configurou-se como a comumente chamada pela alcunha generalista de "História Nova", responsável por grande parte do debate historiográfico atual.

Apesar de se colocarem paralelamente ao marxismo, preferindo o debate direto contra o positivismo, pode-se inferir que os Annales objetivaram constituir-se como uma terceira via entre marxismo e positivismo (DOSSE, 2003). Se as críticas ao marxismo apareciam veladas nas primeiras gerações, na terceira, ao negar qualquer tentativa de totalidade histórica, ela se torna mais clara ${ }^{5}$. Os interesses dos historiadores ligados a essa geração, segundo Burke (1997), transferiu-se da base econômica para superestrutura cultural, deslocamento teórico-metodológico que ficou conhecido pela expressão "do porão ao sótão". Se num primeiro momento essa mudança de interesse se configura como uma crítica a Fernand Braudel, não se pode deixar de ampliá-la ao conjunto das referências que buscam na materialidade e objetividade o fundamento da história e de suas idéias, especialmente o materialismo histórico-dialético.

Concluindo esse breve percurso pela historiografia e seus referenciais teóricometodológicos, evidencia-se que apesar das tentativas de construção de um campo autônomo da História, as diferentes escolas e autores não superaram os limites da especulação filosófica. Quando buscou-se a interpretação da realidade, o conhecimento até certo ponto racional, perdeu-se de vista a necessidade de não apenas compreender a realidade, mas principalmente transformá-la. Como se vê no próximo item, a questão da transformação social se constituiu como fundamento do materialismo histórico.

\section{O MATERIALISMO HISTÓRICO}

Alguns pontos que aproximam o movimento dos Annales à concepção marxista dentro do paradigma iluminista ou "moderno" são indicados por Cardoso (1997), como o reconhecimento da necessidade de uma síntese global e a vinculação da pesquisa histórica com as preocupações do presente, por exemplo. No entanto, ressalta-se também uma diferença fundamental, qual seja, o fato dos historiadores dos Annales não disporem de uma teoria da mudança social. 
Entende-se que esse é o ponto nodal que diferencia o materialismo histórico dos demais referenciais teórico-metodológicos. Os trabalhos de Marx e Engels sustentam e são sustentados por uma teoria da ação, uma "filosofia da práxis", como assinalou Gramsci. O pressuposto para isso foi esboçado na décima primeira das teses de Marx sobre Feuerbach: "Os filósofos têm apenas interpretado o mundo de maneiras diferentes; a questão, porém, é transformá-lo" (MARX, 2009).

Em A ideologia alemã, Marx e Engels esboçam a materialidade e a objetividade com que concebem o trabalho que realizam:

As premissas de que partimos não constituem bases arbitrárias, nem dogmas; são antes bases reais de que só é possível abstrair no âmbito da imaginação. As nossas premissas são os indivíduos reais, a sua ação e as suas condições materiais de existência, quer se trate daquelas que encontrou já elaboradas quando do seu aparecimento quer das que ele próprio criou. Estas bases são portanto verificáveis por vias puramente empíricas. (MARX e ENGELS, 1998, p.10).

No mesmo texto, definem sua concepção de história:

Esta concepção da história tem portanto como base o desenvolvimento do processo real da produção, contritamente a produção material da vida imediata; concebe a forma das relações humanas ligada a este modo de produção e por ele engendrada, isto é, a sociedade civil nos seus diferentes estádios, como sendo o fundamento de toda a história. Isto eqüivale a representá-la na sua ação enquanto Estado, a explicar através dela o conjunto das diversas produções teóricas e das formas da consciência, religião, moral, filosofia, etc., e a acompanhar o seu desenvolvimento a partir destas produções; o que permite naturalmente representar a coisa na sua totalidade (e examinar ainda a ação recíproca dos seus diferentes aspectos). Ela não é obrigada, como acontece à concepção idealista da história, a procurar uma categoria diferente para cada período, antes se mantendo constantemente no plano real da história; não tenta explicar a prática a partir da idéia, mas sim a formação das idéias a partir da prática material; chega portanto, à conclusão de que todas as formas e produtos da consciência podem ser resolvidos não pela crítica intelectual, pela redução à "Consciência de si" ou pela metamorfose em "aparições", em "fantasma", etc., mas unicamente pela destruição prática das relações sociais concretas de onde nasceram as bagatelas idealistas. Não é a Crítica mas sim a revolução que constitui a força motriz da história, da religião, da filosofia ou de qualquer outro tipo de teorias. (MARX e ENGELS, 1998, pp. 35-36)

Guiado, então, pelo objetivo não apenas de conhecer, relatar e compreender a História, mas principalmente "transformar", é que o materialismo histórico se constitui como referencial que compreende a materialidade e a objetividade do conhecimento como premissas essenciais. Essa questão apresenta-se com fundamental importância para o embate que se trava atualmente em relação ao referencial hegemônico calcado no relativismo, no irracionalismo e no subjetivismo, dentro do que Cardoso (1997) assinalou como paradigma pós-moderno, caracterizado, a partir de J. F. Lytoard, pela "morte dos centros" e pela "incredulidade em relação às metanarrativas": 
O primeiro ponto ["morte dos centros], se aplicado à história-disciplina, levaria a afirmar que os pretensos centros (entenda-se: lugares de onde se fala) a partir dos quais se afirmariam as diversas posturas diante da mesma não são legítimos ou naturais, mas sim ficções arbitrárias e passageiras, articuladoras de interesses que não são universais: são sempre particulares, relativos a grupos restritos e socialmente hierarquizados de poder (em outras palavras: não há História; há histórias "de" e "para" os grupos em questão). O segundo ponto [incredulidade em relação às metanarrativas] significa que, no mundo em que agora vivemos, qualquer "metadiscurso", qualquer teoria global, tornou-se impossível de sustentar devido ao colapso da crença nos valores de todo tipo e em sua hierarquização como sendo universais, o que explicaria o assumido niilismo intelectual contemporâneo, com seu relativismo absoluto e sua convicção de que o conhecimento se reduz a processos de semiose e interpretação (hermenêutica) impossíveis de ser hierarquizados de algum modo que possa pretender ao consenso". (CARDOSO, 1997, pp. 39-40).

Afirmar o materialismo histórico, nesse sentido, para além das convenções acadêmicas, constitui como posicionamento político em defesa de um outro projeto de sociedade. Assim, as categorias do materialismo histórico além de se converterem em ferramentas para a interpretação do real, apontam uma estratégia política para a superação do status quo. No próximo item, apresenta-se algumas categorias e pressupostos assumidos na pesquisa histórico-educacional animada pelo materialismo histórico-dialético.

\section{PRESSUPOSTOS TEÓRICO-METODOLÓgICOS PARA A PESQUISA HISTÓRICO-EDUCACIONAL}

Lombardi (2006, pp.77-78) aponta o que considera o entendimento mais adequado sobre a História da Educação: "Creio que o mais adequado é considerar que a História da educação está indicando o estudo do objeto de investigação - a educação - a partir dos métodos e teorias próprias à pesquisa e investigação da ciência da História". Tomando-se essa definição, tem-se que apesar da pesquisa histórico-educacional pressupor a educação como objeto de investigação, a maneira como se apreende esse objeto depende das categorias e pressupostos assumidos no trabalho historiográfico e suas diferentes escolas, referências, tendências e movimentos. Tendo em vista o percurso trilhado neste trabalho, cabe agora esboçar alguns pontos importantes para a definição dos pressupostos teóricometodológicos na pesquisa histórico-educacional animada pelo materialismo históricodialético. Para isso, parte-se da concepção de que a educação é uma prática social inserida numa totalidade concreta e política, econômica e socialmente determinada, compreendendo-se que:

(...) o conhecimento em geral e, especificamente o conhecimento histórico-educacional configura o movimento que parte do todo caótico (síncrese) e atinge, por meio da abstração (análise), o todo concreto (síntese). Assim, o conhecimento que cabe à historiografia educacional produzir consiste em reconstruir, por meio das ferramentas conceituais (categorias) apropriadas, as relações reais que caracterizam a educação como um fenômeno concreto. (SAVIANI, 2007, p. 3). 
Essa consideração é definida por Saviani (2007) como o princípio do caráter concreto do conhecimento histórico-educacional, ao qual se segue outros princípios metodológicos de sua referência teórica, como a perspectiva de longa duração, com a qual, a partir de orientação metodológica proposta por Gramsci, Dermeval Saviani salienta a necessidade de se distinguirem os movimentos orgânicos dos conjunturais, no sentido em que para se captar os movimentos orgânicos (estruturais) é necessário submeter períodos relativamente longos à análise. Em outro trabalho, Saviani (1998, p. 118) afirma que "além da motivação teórica, esse enfoque de longa duração se justifica também por razão prática, isto é, como antídoto à estreiteza de horizontes que tem marcado a trato da questão em nosso meio".

Como decorrência desses dois princípios, Saviani (2007) indica o olhar analíticosintético no trato com as fontes como terceiro princípio, que implica o levantamento e exame atento das informações disponíveis, abrangendo as suas diversas modalidades e articulando-as sincrônica e diacronicamente de modo que não deixe escapar as características e o significado do fenômeno investigado. (SAVIANI, 2007, p.4).

Atenta-se para o fato de que "compreender o fenômeno é atingir-lhe a essência" (CURY, 2000, p.23). Essência aqui despida do caráter idealista e das "ressonâncias metafísicas", tomada como "coisa em-si", considera-se a estrutura em unidade com o fenômeno. Assim, "captar o fenômeno em sua essência não é negar o fenômeno, mas destruir sua pretensa independência e ressaltar sua conexão e unidade com a essência através de oposições e mediações". (CURY, 2000, p.24).

O quarto princípio adotado por Saviani (2007) é o da articulação do singular e do universal, que busca garantir:

(...) o empenho em encontrar a justa relação entre o local, o nacional e o universal. Trata-se aqui não apenas de se evitar tomar o que é local ou nacional pelo nacional e vice-versa, mas também de detectar em que grau o local e o nacional constituem expressões de tendências que se impõe internacionalmente. (SAVIANI, 2007, p.4).

Para trabalhar com esse princípio, leva-se em consideração que a educação é uma totalidade de contradições, ou seja, com o auxílio da categoria da totalidade, pretende-se alcançar "uma visão que seja capaz de conectar dialeticamente um processo particular com outros processos e, enfim, coordená-lo com uma síntese explicativa cada vez mais ampla" (CURY, 2000, p. 27). Nesse sentido, vale destacar também as considerações de Sanfelice (2009, p.198):

Se o singular depende da sua materialidade única, o universal também não é uma abstração: é uma totalidade histórica determinada pelo seu modo de produção, pelas suas relações sociais, pelas suas práticas políticas, culturais, ideológicas e educativas, dentre outras.

Negar categoria da totalidade, assim, seria ocultar as múltiplas determinações da realidade e compreender a educação como um processo particular autônomo, o que vai de encontro ao nosso referencial teórico-metodológico.

Por último, Saviani (2007) explicita sua quinta diretriz teórico-metodológica, o princípio da atualidade da pesquisa histórica: 


\begin{abstract}
(...) que implica a consciência de que, como toda pesquisa, a investigação histórica não é desinteressada. Conseqüentemente, o que provoca o impulso investigativo é a necessidade de responder a alguma questão que nos interpela na realidade presente. Obviamente isso não tem a ver com o "presentismo" nem mesmo com o "pragmatismo". Trata-se, antes, de própria consciência da historicidade humana, isto é, a percepção de que o presente se enraíza no passado e se projeta no futuro. Portanto, eu não posso compreender radicalmente o presente se não compreender as suas raízes, o que implica o estudo de sua gênese. (SAVIANI, 2007, p. 4).
\end{abstract}

Ao compartilhar-se os mesmos princípios metodológicos que Saviani (2007), busca-se trabalhar tendo por base um referencial teórico-metodológico que se contraponha "à estreiteza de horizontes" da perspectiva novidadeira; que busque compreender a essência do fenômeno educativo, suas contradições, mediações e determinações; enfim, proporcione uma maior compreensão da realidade e que ao mesmo tempo aponte uma estratégia política para a transformação dessa mesma realidade.

\title{
CONSIDERAÇÕES FINAIS
}

Percorrendo, mesmo que brevemente, o caminho construído pelas diferentes concepções de História sustentadas por tendências, movimentos e pelas escolas históricas, o presente trabalho buscou contribuir para o entendimento de que a não-neutralidade do conhecimento histórico em geral e do histórico-educacional em particular torna como imperativo a necessidade de se assumir um posicionamento no trato com o objeto de conhecimento. Longe de negar a possibilidade da apreensão da realidade, essa constatação abre um leque de possibilidades, pois pretende investigar a materialidade e as relações concretas que determinam contraditoriamente sujeito e objeto.

Quando falsear o real por meio de posições irracionalistas e subjetivistas se impõe como palavra de ordem, é no empenho em compreender a realidade e suas determinações políticas, econômicas e sociais, que se pode encontrar o germe para as profundas transformações sociais. Para além do mero alegorismo academicista, por tanto, é preciso compreender para revolucionar.

\section{REFERÊNCIAS}

BOURDÉ, Guy, MARTIN, Hervé. As escolas históricas. S.l: Publicações Europa América, 1983. (Forum de história).

BURKE, Peter. A Escola dos Annales (1929-1989): a Revolução Francesa da Historiografia. São Paulo: Fundação Editora da UNESP, 1997. Tradução Nilo Odalia.

CASTANHO, S. E. M. Questões teórico-metodológicas de história cultural e educação. LOMBARDI, J. C.; CASIMIRO, A. P. B. S.; MAGALHÃES, L. D. R. (orgs). História, cultura e educação. São Paulo: Autores Associados, 2006.

CARDOSO, Ciro Flamarion. Introdução - História e Paradigmas Rivais. In: CARDOSO, Ciro Flamario; VAINFAS, Ronaldo (orgs.). Domínios da história: ensaios de teoria e metodologia. Rio de Janeiro: Campus, 1997. 
CURY, Carlos R. Jamil. Educação e Contradição: elementos metodológicos para uma teoria crítica do fenômeno educativo. $7^{\mathrm{a}}$ ed. São Paulo: Cortez, 2000.

DOSSE, François. A História em Migalhas: dos Annales à Nova História. São Paulo: Edusc, 2003.

HOBSBAWM, Eric. Sobre a História. Trad. de Cid Knipel Moreira. São Paulo: Companhia das Letras, 1998.

LOMBARDI, José Claudinei. História e Historiografia da Educação: Fundamentos Teóricos- Metodológicos. In: SCHELBAUER, Analete Regina, LOMBARDI, J. C., MACHADO, M. C. Gomes: (orgs.). Educação em debate: perspectivas, abordagens e historiografia. Campinas - SP: Autores Associados.

LÖWY, M.. Ideologias e ciência social. 8 a .ed. São Paulo, Cortez Editora, 1992.

LÖWY, M. As aventuras de Karl Marx contra o Barão de Münchhausen: marxismo e positivismo na sociologia do conhecimento. $7^{\text {a }}$. ed. São Paulo: Cortez, 2000.

MARX, Karl. Teses sobre Feuerbach. Diponível em: < http://www.marxists.org/portugues/marx/1845/tesfeuer.htm>. Acesso em: 10 de dez. 2009.

MARX, Karl; Engels, Friedrich. A ideologia alemã. Trad. Luis Cláudio de Castro e Costa. São Paulo: Martins Fontes, 1998.

SANFELICE, José Luis. História e historiografia de instituições escolares. Revista HISTEDBR On-line, Campinas, n.35, p. 192-200, set. 2009.

SAVIANI, Dermeval. O Debate Teórico e Metodológico no Campo da História e sua Importância para a Pesquisa Educacional. In: SAVIANI, D; LOMBARD, J. C.; SANFELICE, J. L. História e historia da educação. Campinas: Autores Associados/ HISTEDBR, 1998.

SAVIANI, Dermeval. História das Idéias Pedagógicas no Brasil. Campinas, SP: Autores Associados, 2007.

\footnotetext{
${ }^{1}$ Mestrando em Educação sob orientação do Prof. Dr. José Luis Sanfelice. Membro do Grupo de Estudos e Pesquisas "História, Sociedade e Educação no Brasil" - HISTEDBR (GT/UNICAMP).

${ }^{2}$ Sobre a predominância da concepção positivista de História, Saviani (2000, p.8) levanta a seguinte hipótese: o que se entende por predominância do positivismo não se configuraria exatamente como tal, mas se trataria, antes da persistência da História como narrativa, continuando a tradição que remonta à antiguidade e incorporando, a partir do século passado, procedimentos formais derivados do método científico no processo de levantamento e organização das fontes e na sistematização e exposição das informações. É nesse âmbito que se faria sentir a incidência do positivismo, antes que na concepção de História e na instituição de uma ciência da História”.
} 
${ }^{3}$ Importante lembrar que Löwy (1992; 2000) desenvolve uma tipologia do historicismo, identificando nesse referencial, além do historicismo relativista, o historicismo tradicional e a Sociologia do Conhecimento de Karl Mannheim.

${ }^{4}$ Lombardi (2006, p. 95) aponta que "o grupo dos Annales não se constitui como uma escola que propugnava por um método ou uma teoria da história, mas como um movimento que encorajava várias inovações no âmbito da História, mas que comportava várias matrizes teórico-metodológicas em seu interior".

${ }^{5}$ Pode-se até inferir que as críticas não eram endereçadas diretamente ao materialismo histórico, mas a certo tipo de "marxismo vulgar". Hobsbawn (1998) resume o "marxismo vulgar" em alguns pontos como: o determinismo econômico, a relação mecânica entre infraestrutura e superestrutura, uma leitura positivista, reducionista e parcializada de Marx.

Recebido em 06/09/2010

Aprovado em 7/11/2010 